\title{
TUSSEN VERTALING EN ADAPTATIE EEN KRITISCHE ANALYSE VAN VERTALINGEN VAN NEDERLANDSTALIGE ROMANS IN HET TSJECHISCH EN DUITS IN DE EERSTE HELFT VAN DE TWINTIGSTE EEUW
}

\author{
VERONIKA HORÁČKOVÁ
}

\begin{abstract}
Between translation and adaptation: a critical analysis of translations of Dutch written novels in Czech and German in the first half of the twentieth century

This paper presents an outline of the author's doctoral thesis concerning an analysis of Czech and German translations of Dutch literature in the first half of the twentieth century. The essential issue is whether these texts should be called "translations" or "adaptations". In the first part of this paper the latter terms are defined. Furthermore, two major Czech translators of Dutch literature from this period, Rudolf Jordan Vonka and Lída Faltová, are introduced, as well as the corpus. Finally, a case study of a Czech and German translation of Max Havelaar by Multatuli (1860) is presented.
\end{abstract}

Key words: translation; adaptation; Max Havelaar; Rudolf Jordán Vonka; Lída Faltová

\section{Inleiding}

In mijn proefschrift wil ik het onderzoeksvoorstel presenteren van mijn dissertatie getiteld Tussen vertaling en adaptatie. Een kritische analyse van vertalingen van Nederlandstalige romans in het Tsjechisch en Duits in de eerste helft van de twintigste eeuw. Concreet wil ik onderzoeken in hoeverre Tsjechische en Duitse vertalers van Nederlandse romans zich in de eerste helft van de twintigste eeuw aan het origineel hielden. Vertaalden ze de oorspronkelijke tekst zo nauwkeurig en letterlijk mogelijk? Of gebruikten ze hun creativiteit om de tekst af te stemmen op het doelpubliek en begaven ze zich daarmee op de grens tussen vertaling en adaptatie?

Ik ben me ervan bewust dat de begrippen 'vertaling' en 'adaptatie' op uiteenlopende manieren worden gedefinieerd en dat de grens tussen de twee niet altijd duidelijk getrokken wordt. Daarom is het belangrijk uit te gaan van heldere definities van beide begrippen. Voor mijn dissertatie neem ik de definitie voor het begrip 'vertaling' over van Verstegen (2010): 
"Een vertaling moet met behulp van de semantisch-stilistische mogelijkheden van de eigen taal het algehele effect van het origineel, op basis van een zoveel mogelijk geobjectiveerde interpretatie, zo dicht mogelijk benaderen."

Wat adaptatie betreft, ga ik van de definitie van Van Gorp (2004) uit. Adaptatie is volgens hem een overkoepelend begrip voor:

"[v]arious forms of texts [...] which, depending on the prevailing opinions about texts and text processing, are not considered 'genuine' translations but which still in one way or another represent a primary text with a comparable form and volume".

Ik hanteer dus niet de gebruikelijke definitie, namelijk de transformatie van een kunstwerk naar een ander medium, maar beschouw adaptatie hier als overzetting van een tekst in een andere taal waarbij de doeltekst in hoge mate van het origineel afwijkt.

Ook bij de hier geïntroduceerde definities moet men al meteen constateren dat de grens tussen vertaling en adaptatie moeilijk te trekken is. Van Gorp wijst er dan ook op dat er geen duidelijk verschil kan worden gemaakt tussen deze twee begrippen. Dat komt doordat een brontekstgerichte equivalentie niet helemaal mogelijk is, aangezien verschillende talen verschillende taalsystemen hebben en over andere lexicale (en grammaticale) mogelijkheden beschikken (Van Gorp 2004).

In mijn dissertatie maak ik desondanks een onderscheid tussen de begrippen 'vertaling' en 'adaptatie'. Een vertaling moet volgens mij aan drie criteria voldoen. Ten eerste moet ze "het algehele effect van het origineel" benaderen, zoals Verstegen (2010) vooropstelt. Ook Levý (2012) wijst erop dat de vertaling op het doelpubliek hetzelfde effect zou moeten hebben als de oorspronkelijke tekst op de brontaallezers.

Ten tweede moet de vertaling inhoudelijk met het origineel overeenkomen. In dit verband verwijs ik naar Van Leuven-Zwart (2010) die zegt dat het criterium voor een goede vertaling

"[...] de mate [is] waarin de vertaling een getrouwe afspiegeling is van het origineel; de mate waarin de vertaler, om met Karel van het Reve te spreken, heeft vertaald wat er staat."

Ten derde mag bij een vertaling het loyaliteitsprincipe van Christiane Nord (2006) niet worden geschonden. Volgens dit principe moet de vertaler loyaal zijn, zowel ten opzichte van het doelpubliek, alsook ten opzichte van de auteur van de brontekst. Met andere woorden: de vertaler zou altijd de verwachtingen van de brontekstauteur moeten respecteren.

Indien niet aan deze drie criteria wordt voldaan, beschouw ik de doeltekst niet als een vertaling, maar als een adaptatie.

Om te kunnen vaststellen of de bovengenoemde criteria worden vervuld, zal ik onderzoeken of de vier basiscategorieën van tekstbewerking die ik verderop bespreek in de vertalingen te vinden zijn. Dat echter ook vertalen deel uitmaakt van tekstbewerking, beargumenteert Van Gorp (2004) als volgt:

"[...] the various forms of translation also belong in the group of text processing activities, largely based on a substitution transformation." 
Wat tekstbewerking betreft, hanteer ik de terminologie van Lausberg (2008). De eerste categorie van tekstbewerking is adiectio waarbij er een nieuw element aan het oorspronkelijke geheel wordt toegevoegd. De tweede wordt detractio genoemd. Hier wordt een element van het oorspronkelijke geheel weggelaten. De derde categorie is transmutatio. In dit geval wordt een bepaald element in de tekst verplaatst. Tot slot is er ook nog sprake van immutatio. Bij dit proces wordt er een element door een ander element vervangen.

Ik zal onderzoeken of er in de onderzochte vertalingen sprake van tekstbewerking is en zo ja, welke functie die vervult. Als die tekstbewerking de eerder genoemde criteria voor een vertaling schendt, beschouw ik de tekst als een adaptatie.

Op deze plaats moet ik benadrukken dat het toepassen van adiectio, detractio, transmutatio en immutatio op zichzelf niet verkeerd is, ook niet in vertalingen. Integendeel, het is volkomen gebruikelijk en zelfs gewenst om deze vertaaltransformaties te gebruiken zoals ook Langeveld (2013) constateert. Het wordt echter problematisch als deze transformaties tot een cruciaal verschil tussen het origineel en de vertaling leiden.

\section{Rudolf Jordán Vonka en Lída Faltová als vertalers}

In deze bijdrage wil ik concreet een aantal vertalingen van de Tsjechische vertalers Rudolf Jordán Vonka en Lída Faltová onder de loep nemen. Ik heb juist voor deze twee vertalers gekozen omdat zij tot de meest actieve Tsjechische vertalers van Nederlandse literatuur behoren die in de eerste helft van de twintigste eeuw werkzaam waren. Ze zijn overigens "de eerste [Tsjechische] vertalers die zich op het Nederlands specialiseerden" (Engelbrecht e.a. 2015).

Rudolf Jordán Vonka is op zichzelf een bijzondere figuur. Hij werkte als diplomaat in Nederland en was een groot kenner van Comenius. Daarnaast hield hij zich als amateur bezig met vertalen (Engelbrecht e.a. 2015). De voornaamste, intussen overleden Tsjechische neerlandica Olga Krijtová stelde vast dat Vonka nogal vaak toevoegingen in zijn vertalingen verwerkte. Als voorbeeld noemt ze de roman Pieter Breughel van Felix Timmermans waarin Vonka in de vertaling hele zinnen heeft bijgeschreven. Hoewel de Tsjechische vertaling volgens Krijtová dankzij deze toevoegingen heel mooi klinkt, bestempelt ze Vonka’s ingrepen toch als “vertalersmisdaad” (Šustrová 2008).

Krijtová wijst ook op Vonka’s vertaling van Max Havelaar, in het bijzonder op een passage waarin hij de woorden evenaar en eigenaar verwisselt en Indonesië "rond de heupen van zijn heerser slingert". ${ }^{1}$ Op grond van dit voorbeeld veronderstel ik dat er in Vonka's vertaling van Max Havelaar meer van zulke verkeerde tekstbewerkingen te vinden zijn.

Hoewel Vonka met zijn vele vertalingen een grote bijdrage aan de Tsjechische neerlandistiek heeft geleverd, wordt hij vandaag vanwege dergelijke ingrepen gewoonlijk als een voorbeeld beschouwd van hoe het niet moet. Zo suggereert de vertaler Edgar de Bruin dat in de huidige Tsjechische vertalingen van Nederlandse romans "Vonka's geest leeft" omdat ze, naar zijn zeggen, vaak slordig zijn en vol fouten staan. ${ }^{2}$

Multatuli. Max Havelaar. Dražebni rízení v holandské obchodní společnosti. Svoboda, Praha 1947. p. 326

2 De Bruin, E. "Vonkủv duch v českých překladech nizozemské literatury." In: iLiteratura.cz. 20. 2. 2009. http://www.iliteratura.cz/Clanek/23901/vonkuv-duch-v-ceskych-prekladech-nizozemske-literatury 
De tweede Tsjechische vertaalster aan wie ik aandacht besteed, is Lída Faltová. Faltová heeft in totaal 42 Nederlandse boeken vertaald, dat betekent ongeveer de helft van de Nederlandse boeken die in Tsjechoslowakije in het interbellum werden uitgegeven (Engelbrecht e.a. 2015). Er wordt dan ook gezegd dat zij "toen de belangrijkste Tsjechische literaire vertaalster uit het Nederlands" was. Faltovás vertaling van Kaas van Willem Elsschot is bijvoorbeeld de eerste vertaling van dit boek überhaupt (Engelbrecht 2015).

Wat de kwaliteit van haar vertalingen betreft, schrijft Engelbrecht dat Faltová alles exact vertaalt en dat ze de stijl van Elsschot "vrij trouw weergeeft". Aan de andere kant laat ze volgens Engelbrecht soms complexe woordgroepen weg als die niet van belang zijn (2015). In mijn onderzoek wil ik nagaan of dit verschijnsel ook in haar andere vertalingen aan de orde is en of haar werkwijze vergelijkbaar is met de vertaalwijze van Vonka.

In mijn corpus zal ik uitsluitend romans opnemen die door Vonka of Faltová in het Tsjechisch werden vertaald. Indien er ook een Duitse vertaling bestaat, ga ik die eveneens in het onderzoek betrekken. In mijn corpus wil ik verschillende genres opnemen, bijvoorbeeld Vlaamse streekromans en Indische romans. Mijn corpus bevat op dit moment de volgende titels: Max Havelaar (1860) en De geschiedenis van Woutertje Pieterse (1866-1872) van Multatuli, Het donkere licht (1929) en Kinderen van ons volk (1928) van Antoon Coolen, Pieter Breughel (1928) en Pallieter (1916) van Felix Timmermans, De Witte (1920) en Pastoor Campens Zaliger (1935) van Ernest Claes en Leeuwen hongeren in Napels (1934) van Johan Fabricius. Het corpus bevat vier boeken die door Vonka werden vertaald en vijf werken die in een vertaling van Faltová verschenen zijn (De Witte en Pastoor Campens Zaliger werden in het Tsjechisch in één band gepubliceerd).

\section{Case study - Max Havelaar}

Om meer inzicht in mijn werkwijze te bieden, wil ik tot slot een kleine case study presenteren. Voor deze bijdrage heb ik de eerste twee alinea's van Max Havelaar gekozen. Ik ben van de Nederlandse uitgave van uitgeverij Prometheus uitgegaan die in 2017 is verschenen. Deze editie is gebaseerd op de laatste uitgave die tijdens het leven van Multatuli werd gepubliceerd, namelijk die uit het jaar 1881. Daarbij onderzoek ik de Tsjechische vertaling van Rudolf Jordán Vonka uit het jaar 1947 en de Duitse vertaling van Wilhelm Spohr uit 1901. Hierbij moet worden opgemerkt dat terwijl Vonka zich op de Nederlandse uitgave uit het jaar 1928 heeft gebaseerd, Spohr de uitgave uit het jaar 1860 heeft gebruikt. ${ }^{3}$

Bij wijze van voorbeeld laat ik aan de hand van een analyse van de eerste alinea's van het boek verschillende vormen van tekstbewerking zien. Vanwege het korte bestek van deze bijdrage ga ik alleen op een aantal gevallen in.

Allereerst geef ik een voorbeeld van toevoeging. Batavus Droogstoppel die zichzelf in de eerste alinea's van de roman voorstelt, zegt in de volgende woorden dat hij niet van romans houdt: "[...] ik houd er zelfs niet van, iets dergelyks te lezen [...]". ${ }^{4}$ De Tsjechische versie is wat omslachtiger: “[...] já sám, přiznávám se, nemám zvyk, abych něco

3 In mijn dissertatie zal ik uiteraard met de edities werken waarop Vonka en Spohr zich hebben gebaseerd.

4 Multatuli. Max Havelaar of de koffieveilingen der Nederlandsche Handelmaatschappy. Prometheus, Amsterdam 2017. p. 45 
podobného četl, abych se k čtení něčeho podobného odhodlal [...]" 5 (“ik zelf, ik beken het, heb niet de gewoonte om iets dergelijks te lezen, om mezelf ervan te overtuigen iets dergelijks te lezen").

Als voorbeeld van een verkeerde vervanging kan ik het volgende zinsdeel noemen waar overigens ook Olga Krijtová op wijst. ${ }^{6}$ In het origineel staat dat Droogstoppel "een paar riem papier extra"7 heeft besteld, maar in de Tsjechische versie lezen we: "několik papírů s rýmovačkami"8 ("een paar stukken papier met rijmpjes"). Vonka heeft blijkbaar het woord "riem" - wat een oude handelsmaat voor papier is - met het woord "rijm" verward. Het is trouwens verbazingwekkend dat Vonka dit niet vreemd vond aangezien uit het boek duidelijk blijkt dat Droogstoppel niet van poëzie houdt.

Een voorbeeld dat boekdelen spreekt, is de volgende zin over schrijver Hieronymus van Alphen en zijn morele stellingen: "Hy was al dood, geloof ik, toen hy ons vertelde dat myn vader myn beste vrind was - ik hield meer van Pauweltje Winser, die naast ons woonde in de Batavierstraat - en dat myn kleine hond zoo dankbaar was." Vonka vertaalt de zin vrij eigenaardig: "Jistěže už zemřel, aspoň si myslím, že už zemřel, to je ten, co nám vypravoval, že můj otec byl můj nejlepší př́tel... já tedy dám více na to, co říká Pavlík Winser. Ten zůstával blízko našich na Batavské ulici a měl mi zač děkovat, dostal ode mne štěně."10 ("Natuurlijk is hij al gestorven, tenminste geloof ik dat hij al is gestorven, dat is degene die ons vertelde dat mijn vader mijn beste vriend was... ik waardeer meer dat wat Pauweltje Winser zegt. Die bleef dichtbij mijn ouders in de Batavierstraat en kon mij dankbaar zijn, hij kreeg van mij een hondje."). In het origineel is er geen sprake van dat Pauweltje van Droogstoppel een hond krijgt. Bovendien hield Droogstoppel van Pauweltje als persoon en niet van wat hij zei.

Ook de volgende passage gaat over Van Alphen. Droogstoppel vertelt hier dat hij al als kind Van Alphen als een oplichter beschouwde. "Ik dacht dikwyls als kind: 'man, ik wilde u graag eens ontmoeten, en als ge my de marmerknikkers weigerde, die ik u vragen zou, of myn naam voluit in banket - ik heet Batavus - dan houd ik u voor een leugenaar."'11 Problematisch is vooral het gedeelte met "myn naam voluit in banket". Onder "banket" wordt een soort deeg verstaan waaruit gebak onder andere in de vorm van letters wordt gemaakt.

In het Duits wordt deze passage juist geïnterpreteerd en vertaald als "meinen vollständigen Namen in Buchstabenbretzeln". ${ }^{12}$ Vonka heeft echter de betekenis van de hele zin niet begrepen. Zo staat in de Tsjechische vertaling dat Droogstoppel Van Alphen "luid en met zijn volle naam" tijdens een feestmaal tot een lottospel zou uitdagen. ${ }^{13}$ Het woord "banket" betekent weliswaar naast "deeg" ook "feestmaal", maar het past helemaal niet in deze context. Bovendien voegt Vonka hier opnieuw hele zinsdelen toe.

5 Multatuli. Max Havelaar. Dražební řizení v holandské obchodní společnosti. p. 13

6 Zie De Bruin (2009).

7 Multatuli. Max Havelaar of de koffieveilingen der Nederlandsche Handelmaatschappy. p. 45

8 Multatuli. Max Havelaar. Dražební ŕízení v holandské obchodní společnosti. p. 13

9 Multatuli. Max Havelaar of de koffieveilingen der Nederlandsche Handelmaatschappy. p. 46

10 Multatuli. Max Havelaar. Dražební řizení v holandské obchodní společnosti. p. 14

11 Multatuli. Max Havelaar of de koffieveilingen der Nederlandsche Handelmaatschappy. p. 45-46

12 Multatuli. Max Havelaar. J.C.C. Bruns Verlag, Minden 1901. [reprint Forgotten Books] p. 2

13 Multatuli. Max Havelaar. Dražební ř́zení v holandské obchodní společnosti. p. 14 
Grofweg kunnen we zeggen dat de Duitse vertaling veel dichter bij het origineel staat. Af en toe zijn er ook hier wel kleinere toevoegingen te vinden. Zo staat in het origineel "De fout begint al van Van Alphen af [...]"14 en in het Duits: "Der Fehler fängt schon bei unserm Van Alphen an [...]"15. Het toevoegen van het woord "unserm" ("onze") suggereert dat Droogstoppel en zijn familie met Van Alphen en zijn werk vertrouwd waren.

Men kan concluderen dat in de beginalinea's van de Nederlandse en Duitse versie Droogstoppel zakelijk, streng en droog overkomt zoals zijn naam suggereert. Door Vonka's toevoegingen laat de Tsjechische Droogstoppel zich echter niet zo zakelijk uit. Daardoor krijgt de Tsjechische lezer een ander beeld van hem dan de Nederlandse en Duitse lezer. Bovendien hebben sommige passages in de Tsjechische vertaling vanwege onjuiste vervangingen een andere betekenis dan in het origineel en in de Duitse vertaling.

\section{Conclusie}

Op basis van de bovengenoemde voorbeelden vermoed ik dat de Tsjechische versie van Max Havelaar niet geheel getrouw is aan het origineel. Daarnaast meen ik dat hier het loyaliteitsprincipe wordt geschonden en dat de vertaling op de lezer dan ook niet hetzelfde effect heeft als de oorspronkelijke tekst. De Tsjechische tekst zou daarom in de optiek van mijn dissertatie als adaptatie kunnen worden bestempeld.

De Duitse versie is daarentegen - met de woorden van Van Leuven-Zwart (2010) "een getrouwe afspiegeling [...] van het origineel" en heeft daarom op de lezer hetzelfde effect als het origineel. Bovendien wordt hier het loyaliteitsprincipe gerespecteerd. In dit geval gaat het dus om een pure vertaling.

Op grond van de vertaling van de eerste alinea's vermoed ik niet alleen dat ook de rest van Vonka's vertaling van Max Havelaar een groot aantal verkeerde vervangingen en toevoegingen bevat, maar dat dit ook voor zijn andere vertalingen geldt. Daarnaast veronderstel ik dat dit niet het geval is bij de vertalingen van Faltová aangezien zij in tegenstelling tot Vonka een professionele vertaalster was. Uiteraard zou ik ook hier een gelijksoortige vertaling van de eerste alinea's moeten uitvoeren. Tot slot neem ik aan dat de Duitse vertalingen van de onderzochte romans dichter bij het origineel zullen staan omdat het Duits nauwer verwant is met het Nederlands en daardoor alleen al een trouwere vertaling mogelijk maakt. In mijn promotieonderzoek zal ik deze hypotheses toetsen en voor de resultaten een verklaring proberen te geven, mede op basis van de context waarin de vertalingen zijn ontstaan.

\section{BIBLIOGRAFIE}

DE BRUIN, EDGAR (2009). "Vonkův duch v českých překladech nizozemské literatury”, in: iLiteratura.cz. 20. 2. 2009. http://www.iliteratura.cz/Clanek/23901/vonkuv-duch-v-ceskych-prekladech-nizozemske -literatury.

14 Multatuli. Max Havelaar of de koffieveilingen der Nederlandsche Handelmaatschappy. p. 45

15 Multatuli. Max Havelaar. J.C.C. Bruns Verlag. p. 2 
ENGELBRECHT, WILKEN (2015). "Kázus Kaas - recepce děl Elsschota v češtině”, in: Jana Engelbrechtová (red.): Sýr. Mezinárodní recepce novely Kaas. Ukázky prvního českého překladu. Olomouc: Vydavatelství Univerzity Palackého.

ENGELBRECHT, WILKEN e.a. (2015), Dějiny nizozemské a vlámské literatury. Praha: Academia.

LANGEVELD, ARTHUR (2013). "Vertaaltransformaties", in: Vertalen wat er staat. Amsterdam/Antwerpen: Atlas Contact, 68-123.

LAUSBERG, HEINRICH (2008). Handbuch der literarischen Rhetorik. Stuttgart: Franz Steiner Verlag.

LEVÝ, JIŘÍ (2012). Umění prekeladu. Praha: Apostrof.

MULTATULI (2017). Max Havelaar of de koffieveilingen der Nederlandsche Handelmaatschappy. Amsterdam: Prometheus.

MULTATULI (1947). Max Havelaar. Dražební řizení v holandské obchodní společnosti. Praha: Svoboda.

MULTATULI (1901). Max Havelaar. Minden: J.C.C. Bruns Verlag [reprint Forgotten Books].

NORD, CHRISTIANE (2006). "Das Verhältnis des Zieltexts zum Ausgangstext", in: Mary Snell-Hornby e.a. (red.): Handbuch Translation. Tübingen: Stauffenburg Verlag.

ŠUSTROVÁ, PETRUŠKA (2008). “Olga Krijtová”, in: Služebníci slova. Praha: Pulchra.

VAN BORK, G. J. e.a. (2012-2017). Algemeen letterkundig lexicon, in: DBNL. http://www.dbnl.org/tekst /dela012alge01_01/index.php

VAN GORP, HENDRIK (2004). “Translation and comparable transfer operations”, in: Übersetzung, Translation, Traduction. Ein internationales Handbuch zur Übersetzungsforschung. Band 1. Berlin New York: Walter de Gruyter, 62-68.

VAN LEUVEN-ZWART KITTY (2010). “Een goede vertaling, wat is dat?”, in: Tom Naaijkens e.a. (red.): Denken over vertalen. Tekstboek vertaalwetenschap. Nijmegen: Vantilt, 225-234.

VERSTEGEN, PETER (2010). "Vertaalcriteria en vertaalkritiek", in: Tom Naaijkens e.a. (red.): Denken over vertalen. Tekstboek vertaalwetenschap. Nijmegen: Vantilt, 213-223.

\section{MEZI PŘEKLADEM A ADAPTACÍ: KRITICKÁ ANALÝZA PŘEKLADŮ NIZOZEMSKY PSANÝCH NOVEL V ČESKÉM A NĚMECKÉM PŘEKLADU V PRVNÍ POLOVINĚ DVACÁTÉHO STOLETÍ}

Tento prríspěvek představuje přehled autorovy disertační práce týkající se analýzy českých a německých překladů nizozemské literatury v první polovině 20. století. Základní otázkou je, zda by tyto texty měly být nazývány „překlady“, nebo spíše „adaptace“. V první části článku jsou tyto termíny definovány. Dále příspěvek představuje dva významné české překladatele nizozemské literatury - Rudolfa Jordána Vonka a Lídu Faltovou, spolu s výběrem jejich překladů. Na závěr je prezentována př́padová studie českého a německého překladu Multatuliho románu Max Havelaar (1860).

Veronika Horáčková

Masarykova Univerzita

E-mail:399625@mail.muni.cz 